doi: mkts.v24i2.18996

\title{
Kajian Penambahan RejIRE pada Aspal Modifikasi Crumb Rubber serta Kinerjanya pada Campuran Beraspal Panas
}

\author{
* Sri Mulyani, Nono, Nyoman Suaryana \\ Pusat Penelitian dan Pengembangan Jalan dan Jembatan, \\ Kementerian Pekerjaan Umum dan Perumahan Rakyat, Bandung \\ ${ }^{*}$ sri.mulyani@pusjatan.pu.go.id
}

Received: 18 Mei 2018 Revised: 15 November 2018 Accepted: 19 November 2018

\begin{abstract}
Asphalt polymer has superior characteristics than conventional asphalt. Styrene Butadiene Styrene (SBS) is a polymer that has proven its performance in heavy traffic, but it must be imported and expensive. Crumb rubber have high potential to be used as an asphalt modifier. Asphalt modified crumb rubber has high viscosity and is not homogeneous, so that the utilization cannot be delayed. This reduces workability in the field. This study aims to obtain asphalt modified crumb rubber which is easier to use by adding materials that do not affect its performance. RejIRE is a low viscosity additive to restore the properties of bitumen on crumb rubber modified. Experiments were carried out by adding variations in RejIRE levels to crumb rubber modified asphalt to determine its characteristics. Continued investigation of the performance of hot paved mixtures for wearing courses compared to asphalt mixtures with Pen 60/70 asphalt and SBS modified asphalt mixtures. The result is the addition of $0.75 \%$ RejIRE on asphalt crumb rubber modification have high workability. Overall the performance of the mix with SBS modified asphalt is better, but the mixture of hot paved with modified asphalt crumb rubber has a resistance to permanent deformation superior to the other paved mixtures.
\end{abstract}

Keywords: Crumb rubber, hot mix asphalt performance, modified asphalt, fatigue, resistance to deformation

\begin{abstract}
Abstrak
Aspal polimer memiliki karakteristik yang lebih unggul dibanding aspal konvensional. Styrene Butadiene Styrene (SBS) merupakan polimer yang telah teruji kinerjanya pada lalu lintas berat, namun untuk mendapatkannya harus impor akibatnya mahal. Parutan ban bekas (crumb rubber) memiliki potensi tinggi untuk dijadikan modifier aspal. Aspal modifikasi crumb rubber memiliki viskositas tinggi dan tidak homogen, akibat penyerapan minyak aromatik ringan aspal selama pencampuran, sehingga tidak bisa ditunda pemanfaatannya. Hal ini mengurangi workability di lapangan. Penelitian ini bertujuan agar didapatkan aspal modifikasi crumb rubber yang lebih mudah digunakan dengan menambahkan bahan yang tidak mempengaruhi kinerjanya. RejIRE adalah aditif dengan viskositas rendah untuk mengembalikan sifat-sifat aspal pada aspal modifikasi crumb rubber. Eksperimen dilakukan dengan penambahan variasi kadar RejIRE terhadap aspal modifikasi crumb rubber untuk mengetahui karakteristiknya. Dilanjutkan penyelidikan kinerja campuran beraspal panas untuk wearing course dibandingkan campuran beraspal dengan aspal Pen 60/70 dan campuran beraspal menggunakan aspal imodifikasi SBS. Hasilnya penambahan 0,75\% RejIRE pada aspal modifikasi crumb rubber membuat viskositasnya rendah dan lebih homogen. Secara keseluruhan kinerja campuran beraspal dengan aspal modifikasi SBS lebih baik, namun campuran beraspal panas dengan aspal modifikasi crumb rubber memiliki ketahanan terhadap deformasi permanen lebih unggul daripada dua campuran beraspal lainnya.
\end{abstract}

Kata kunci: Crumb rubber, kinerja campuran beraspal panas, aspal modifikasi, retak lelah, ketahanan terhadap deformasi 


\section{Pendahuluan}

\section{Aspal modifikasi polimer}

Peningkatan volume dan beban kendaraan serta kondisi Indonesia yang memiliki iklim tropis merupakan penyebab banyaknya ditemukan kerusakan jalan. Penggunaan aspal yang tidak sesuai sering memberikan indikasi kerusakan dini berupa alur, gelombang, retak dan naiknya aspal ke permukaan (Suroso, 2008). Berbagai macam modifikasi untuk meningkatkan mutu aspal telah dilakukan untuk mengatasi permasalahan tersebut. Bahan dari jenis elastomer merupakan salah satu yang digunakan untuk memodifikasi aspal seperti SBS dan SBR dengan tujuan meningkatkan keelastisan aspal dengan nilai elastic recovery yang tinggi sehingga menjadi lebih tahan terhadap deformasi permanen maupun retak, karena bahan tersebut memiliki daya tahan terhadap panas serta elastisitas yang tinggi (Hermadi \& Ronny, 2015). Walaupun demikian, penggunaan modifier sintetis ini terbatas karena harga yang mahal dan harus diimpor. Seperti aspal modifikasi polimer SBS yang merupakan produk aspal komersial yang sudah ditambahkan additif sehingga kualitasnya lebih baik dibandingkan aspal konvenisonal yang sering digunakan di Indonesia (Fauziah et al., 2017). Maka langkah pemanfaatan bahan alternatif yang lebih murah dan ketersediaannya berlimpah perlu dikaji.

\section{Penelitian sebelumnya}

Percobaan pembuatan aspal yang dimodifikasi $15 \%$ crumb rubber terhadap total campuran, kondisi optimum pencampuran aspal dengan crumb rubber untuk skala laboratorium dengan kecepatan pengadukan $6000 \mathrm{rpm}$ didapatkan pada temperatur $140^{\circ} \mathrm{C}$ diaduk selama 60 menit. Percobaan tersebut menghasilkan aspal modifikasi dengan penetrasi yang cukup rendah yaitu 42,2 dmm dan titik lembek $57^{\circ} \mathrm{C}$ (Mulyani \& Hamdani, 2017). Pada penelitian tersebut dapat disimpulkan bahwa jika crumb rubber digunakan sebagai bahan modifier aspal dengan cara wet process yaitu mencampurkan aspal keras pen 60/70 dengan crumb rubber dengan komposisi tertentu hasilnya tidak homogen sehingga kemungkinan besar penggunaannya untuk skala lapangan harus langsung, tidak bisa disimpan terlebih dahulu (storage). Hal ini disebabkan oleh hilangnya sebagian senyawa aromatik ringan aspal akibat diserap oleh partikel crumb rubber selama proses berlangsung. Maka dilakukan studi lebih lanjut untuk mendapatkan aspal dengan crumb rubber yang homogen secara wet process salah satu upayanya adalah menambahkan aditif yang berfungsi untuk menggantikan senyawa aromatik ringan tersebut. Salah satu indikator aspal modifikasi homogen bisa diuji dengan parameter stabilitas penyimpanan: perbedaan titik lembek $\left({ }^{\circ} \mathrm{C}\right)$ nilainya tidak boleh lebih besar dari $2^{\circ} \mathrm{C}$.

\section{Crumb rubber}

Crumb rubber adalah hasil sampingan dari proses pemotongan dan penggilingan ban bekas (Ambaiowei \& Tighe, 2013). Metode pemotongan baik secara ambient process (pengolahan ban bekas dengan temperatur ruangan) maupun cryogenic process (menambahkan cairan nitrogen pada saat pengolahan ban bekas untuk membekukan ban sehingga menjadi getas pada temperatur di bawah $-80^{\circ} \mathrm{C}$ ) (Mulyani \& Hamdani, 2017). Metode ambient lebih luas penggunaannya daripada metode cryogenic, dan crumb rubber hasil metode ambient memiliki distribusi ukuran partikel bervariasi yang dapat dicapai dan ukuran partikel maksimum bisa ditentukan (Bahia et al., 2012).

\section{Reologi aspa}

Pengujian viskositas diperlukan guna mengetahui kemampuan pengaliran aspal sehingga tingkat kemudahan pencampuran dan pemadatan campuran beraspal di lapangan dapat diketahui (Nono, 2016). Penambahan bahan polimer akan meningkatkan kekentalan aspal sehingga pemadatan campuran beraspal panas dengan aspal modifikasi polimer akan lebih sulit mencapai kepadatan tertentu dibandingkan dengan campuran beraspal biasa (Kusnianti \& Affandi, 2013). Nilai viskositas aspal digunakan untuk menentukan temperatur pencampuran dan pemadatan (Suaryana \& Kusnianti, 2016). Temperatur pencampuran pada $170 \pm 20 \mathrm{CSt}$ sedangkan untuk temperatur pemadatan pada $280 \pm 30 \mathrm{CSt}$ sesuai dengan ketentuan Asphalt Institute. Menurut Kusnianti \&Affandi (2013) batasan viskositas aspal untuk penentuan temperatur pemadatan, tidak dapat diterapkan untuk campuran beraspal dengan bahan tambah, lebih cocok didasarkan batasan kepadatan atau VIM yang ingin dicapai melalui percobaan Marshall. Maka dalam penelitian ini digunakan metode batasan kepadatan atau VIM yang ingin dicapai melalui percobaan Marshall dalam penentuan temperatur pencampuran dan pemadatan.

Deformasi yang terjadi pada perkerasan beraspal terkait erat dengan sifat-sifat reologi aspal. Alat Dynamic Shear Rheometer (DSR) digunakan untuk menguji aspal dan mengukur sifat reologinya termasuk complex shear modulus $\left(\mathrm{G}^{*}\right)$ dan phase angle $(\delta)$ pada temperatur menengah sampai tinggi. Karakter tersebut digunakan untuk 
mengetahui karakter viskos dan elastic dari aspal. Complex shear modulus merupakan pengukuran total ketahanan suatu material terhadap deformasi ketika diberi beban sinusoidal. $\mathrm{G}^{*}$ terdiri dari komponen elastik (dapat pulih kembali) dan viskos (tidak dapat pulih kembali). Phase angle merupakan indikator dari besaran relatif komponen elastik dan viskos. Nilai keduanya tergantung dari temperatur pengujian dan frekuensi pembebanan. Pengujian ini dilakukan untuk mengetahui kemampuan aspal dalam menahan deformasi permanen dan retak lelah. Pengujian DSR dilakukan pada aspal baru yang belum mengalami penuaan, aspal yang telah dilakukan pengujian RTFOT dan juga PAV (Pavement Interactive, 2016).

\section{Kinerja campuran beraspal}

Menurut Nono \& Mahmud (2016) kinerja campuran beraspal panas di lapangan dipengaruhi oleh lima karakteristik campuran padat yang bisa dianalisis di laboratorium antara lain berat isi, rongga dalam campuran, rongga dalam agregat, rongga terisi aspal, dan kadar aspal. Kinerja campuran beraspal panas disumbangkan oleh beberapa sifat yang mencakup stabilitas, keawetan, kekedapan, kemudahan dikerjakan, kelenturan, ketahanan lelah, dan kekesatan.

Nono \& Mahmud (2016) melanjutkan bahwa berat campuran beraspal panas yang tinggi akan menghasilkan campuran beraspal panas yang tahan lama. Rongga udara dalam campuran (VIM) merupakan rongga udara yang diperlukan oleh campuran beraspal panas untuk menerima pemadatan tambahan oleh lalu lintas, makin kecil rongga udara maka campuran beraspal akan semakin padat, spesifikasi menentukan nilai rongga udara serendah mungkin biasanya untuk ACWC (lapis permukaan) maksimal 8\%. Agar campuran beraspal panas awet maka rongga dalam agregat (VMA) harus memenuhi persyaratan.

Fungsi utama rongga terisi aspal adalah membatasi nilai maksimum rongga dalam agregat dan selanjutnya membatasi nilai maksimum kadar aspal, juga mencegah rongga dalam campuran berada di dekat batas minimum kriteria. Sedangkan kadar aspal $(\mathrm{Pb})$ merupakan faktor kritis terhadap kinerja campuran beraspal panas, sehingga penentuan kadar aspal yang dipilih harus yang optimum, yang mana sangat tergantung pada sifat agregat (gradasi dan penyerapan).

Stabilitas dinamis adalah hubungan antara jumlah lintasan dan deformasi yang terjadi pada pengujian dengan alat wheel tracking dan digunakan sebagai parameter ketahanan campuran beraspal terhadap deformasi permanen (Suaryana, 2015). Pengujian ini dilakukan pada temperatur $60^{\circ} \mathrm{C}$ selama 60 menit sebanyak 1260 lintasan.

Modulus resilien merupakan modulus elastisitas yang digunakan dengan teori elastisitas. Pada dasarnya material perkerasan tidak elastik tapi mengalami deformasi permanen setelah pembebanan. Namun jika beban tersebut kecil dibanding dengan kekuatan material (dengan sejumlah besar pengulangan pembebanan), deformasi yg terjadi pada setiap pembebanan hampir kembali ke posisi sempurna dan hal ini bisa dianggap elastik (Huang, 2004). Selain faktor tegangan dan regangan yang terjadi, faktor temperatur dan waktu pembebanan juga memberikan pengaruh terhadap nilai modulus resilien. Semakin tinggi temperatur maka semakin kecil nilai modulus resilien. Hal ini disebabkan karena aspal bersifat visco-elastic dimana sifatnya dapat berubah dari viscous ke elastic maupun sebaliknya karena perubahan temperatur.

Pengujian ketahanan campuran beraspal terhadap kelelahan akibat beban berulang (fatigue) dilakukan dengan metoda strain control, mengingat campuran ini digunakan untuk lapisan permukaan yang cukup tipis, pada berbagai besaran strain antara 700-250 mikron (Affandi, 2009).

\section{Keterbaruan Penelitian}

Hal yang menjadi keterbaruan dalam penelitian ini adalah penggunaan aditif RejIRE.

RejIRe merupakan aditif berbasis minyak yang memiliki viskositas rendah yang mempunyai fungsi meningkatkan ketahanan retak pada temperature rendah dan deformasi permanen (lehtimaki, 2012 dalam Nono, 2017). Penambahan aditif dengan kadar bervariasi dilakukan pada saat pencampuran. Selama ini RejIRE digunakan sebagai peremaja pada Recycling Asphalt Pavement. Pemanfaatan crumb rubber hingga 15\% dari aspal dan dilakukan hingga penyelidikan kinerja campuran beraspal. Pada penelitian sebelumnya (mulyani \& Hamdani, 2017) pemanfaatan crumb rubber kadar $15 \%$ dari total aspal dan dilakukan hingga penyelidikan kinerja aspalnya saja, belum ke kinerja campuran beraspal.

Tujuan penelitian ini adalah mengkaji pengaruh penambahan RejIRE pada aspal modifikasi crumb rubber terhadap karakteristik sifat bahan pengikat aspal dan kinerja aspal modifikasi crumb rubber pada campuran beraspal di laboratorium dibandingkan dengan aspal konvensional dan aspal modifikasi SBS. 
Tabel 1. Perbandingan karakteristik aspal Pen $60 / 70$ dengan aspal modifikasi SBS

\begin{tabular}{|c|c|c|c|c|c|}
\hline \multirow[b]{2}{*}{ Jenis pengujian } & \multirow[b]{2}{*}{ Metode pengujian } & \multicolumn{2}{|c|}{ Aspal pen 60/70 } & \multicolumn{2}{|c|}{ Aspal modifikasi SBS } \\
\hline & & $\begin{array}{c}\text { Hasil } \\
\text { pengujian }\end{array}$ & $\underset{*)}{\text { Spesifikasi }}$ & $\begin{array}{c}\text { Hasil } \\
\text { pengujian }\end{array}$ & Spesifikasi $^{*}$ \\
\hline $\begin{array}{l}\text { Penetrasi pada } 25^{\circ} \mathrm{C}, 100 \mathrm{~g}, \\
5 \text { detik (dmm) }\end{array}$ & SNI $2456: 2011$ & 63 & $60-70$ & 57 & $\geq 40$ \\
\hline Viskositas pada $135^{\circ} \mathrm{C}(\mathrm{cSt})$ & SNI $7729: 2011$ & 406 & $\geq 300$ & - & - \\
\hline Titik lembek $\left({ }^{\circ} \mathrm{C}\right)$ & SNI $2434: 2011$ & 49,0 & $\geq 48$ & 55,5 & $\geq 54$ \\
\hline Daktilitas pada $25^{\circ} \mathrm{C}, 5 \mathrm{~cm} /$ menit $(\mathrm{cm})$ & SNI $2432: 2011$ & $>140$ & $\geq 100$ & $>140$ & $\geq 100$ \\
\hline Titik nyala $(\mathrm{COC})\left({ }^{\circ} \mathrm{C}\right)$ & SNI $2433: 2011$ & 326 & $\geq 232$ & 310 & $\geq 232$ \\
\hline Kelarutan dalam $\mathrm{C}_{2} \mathrm{HCl}_{3}(\%)$ & SNI 06-2438-1991 & 99,9459 & $\geq 99$ & 99,9 & $\geq 99$ \\
\hline Berat jenis(-) & SNI $2441: 2011$ & 1,0391 & $\geq 1,0$ & 1,038 & $\geq 1,0$ \\
\hline Kehilangan berat (TFOT) $(\%)$ & SNI 06-2440-1991 & 0,0292 & $\leq 0,8$ & 0,0130 & $\leq 0,8$ \\
\hline Penetrasi setelah TFOT (\%) & SNI $2456: 2011$ & 80 & $\geq 54$ & 82,5 & $\geq 54$ \\
\hline Daktilitas setelah TFOT & SNI $2432: 2011$ & $>100$ & $\geq 100$ & $\geq 140$ & $\geq 25$ \\
\hline $\begin{array}{l}\text { Stabilitas penyimpanan : perbedaan titik } \\
\text { lembek }\left({ }^{\circ} \mathrm{C}\right)\end{array}$ & $\begin{array}{c}\text { ASTM D } 5976 \\
\text { part.6.1 }\end{array}$ & - & - & 1,2 & $\leq 2,2$ \\
\hline
\end{tabular}

\section{Metode}

Metode penelitian yang digunakan adalah metode eksperimental, dengan melakukan percobaan dan pengamatan di laboratorium, antara lain sebagai berikut: (1) Mempelajari hasil penelitian yang telah dilakukan pada tahun sebelumnya. (2) Melakukan pencampuran aspal crumb rubber dengan cara wet process dengan tambahan variasi kadar aditif yaitu $0,75 \%, 0,9 \%, 1 \%, 2 \%$ dan $3 \%$, kemudian menguji sifat-sifatnya beserta viskositas dan reologinya, menganalisis hasil dan menentukan aspal mana yang akan digunakan untuk campuran beraspal. (3) Melakukan pengujian karakteristik bahan agregat yang akan digunakan untuk campuran beraspal. (4) Membuat Design Mix Formula (DMF) untuk campuran beraspal panas dengan menggunakan metode Marshall agar diperoleh kadar aspal optimum dan target kepadatan. Dilanjutkan dengan pengujian stabilitas dinamis, modulus resilien, dan fatigue. Analisis hasil membandingkan dengan spesifikasi aspal crumb rubber.

\section{Hasil dan Pembahasan}

\section{Sifat aspal Pen 60/70.}

Aspal yang digunakan untuk kegiatan ini adalah aspal Pertamina Pen 60/70. Karakteristik aspal tersebut disajikan pada Tabel 1 dan memenuhi persyaratan sesuai Spesifikasi Campuran Beraspal Panas Bergradasi Menerus (BSN, 2015).

Sifat fisik aspal modifikasi styrene butadiene styrene (SBS)

Aspal modifikasi SBS merupakan aspal yang ditambahkan SBS dan digunakan untuk memenuhi kebutuhan pembangunan jalan bervolume lalu lintas berat (Pangaraya, 2015). Karakteristik aspal modifikasi SBS dan spesifikasinya disajikan pada Tabel 1. Dapat dilihat bahwa baik aspal Pen 60/70 dan aspal modifikasi SBS memenuhi persyaratan.

\section{Karakteristik RejIRE}

Bahan yang dibutuhkan untuk mendukung aspal crumb rubber adalah bahan yang memiliki kegunaan mendispersikan dan melunakkan butiran crumb rubber agar dapat bereaksi dengan aspal dengan baik, sehingga didapatkan aspal modifikasi yang lebih stabil. Bahan aditif yang digunakan adalah RejIRE (Rejuvenator Institute of Road engineering) yang merupakan bahan peremaja aspal dari Recycling Asphalt Pavement (RAP). Dalam bahan ini terkandung dan tersusun senyawa aromatik ringan untuk menggantikan senyawa aromatik ringan yang menguap (Nono, 2017) dan terserap oleh crumb rubber saat proses pembuatan aspal modifikasi. Karakteristik bahan aditif disajikan pada Tabel 2.

Tabel 2. Sifat bahan peremaja RejIRE

\begin{tabular}{lr}
\hline \multicolumn{1}{c}{ Jenis pengujian } & \multicolumn{1}{c}{ Nilai } \\
\hline Viskositas pada $25^{\circ} \mathrm{C} ; \mathrm{cSt}$ & 276,000 \\
Viskositas pada $60^{\circ} \mathrm{C} ; \mathrm{cSt}$ & 39,100 \\
Titik nyala; ${ }^{\circ} \mathrm{C}$ & 296,000 \\
Berat jenis & 0,996 \\
\hline Sumber: Nono, 2017 &
\end{tabular}

\section{Karakteristik aspal crumb rubber}

Menurut Shatnawi (2011), aspal crumb rubber merupakan gabungan yang tidak homogen terdiri dari cairan aspal dan partikel padat crumb rubber, yang mana saat berinteraksi partikel crumb rubber menyerap sebagian minyak dari aspal dan mengembang, sehingga meningkatkan viskositas dan kekakuan dari aspal crumb rubber. Sehingga 
dalam pembuatannya dibutuhkan aditif yang bisa menggantikan minyak dari aspal dan menurunkan nilai viskositas dari aspal crumb rubber yang dihasilkan. Proses pembuatan aspal modifikasi crumb rubber menggunakan alat tertentu dengan menambahkan crumb rubber pada aspal yang telah dipanaskan pada $140^{\circ} \mathrm{C}-155^{\circ} \mathrm{C}$, dengan kecepatan pengadukan $4000 \mathrm{rpm}$ selama 60 menit. Karakteristik aspal crumb rubber dengan beberapa variasi kadar RejIRE dengan dibandingkan persyaratan yang diminta oleh spesifikasi dan standar ditampilkan pada Tabel 3. Bina Marga (2015) telah mengeluarkan Skh-3.6.3.2 yaitu spesifikasi khusus mengenai campuran beraspal panas dengan aspal yang dimodifikasi crumb rubber atau asbuton. ASTM D6114 (2009) meliputi Asphalt-rubber binder, terdiri dari campuran beraspal, ground recycled tire rubber dan bahan tambah yang dibutuhkan untuk binder pada perkerasan jalan. Yang terakhir adalah dari Caltrans (2015) di mana Caltrans telah mengembangkan dan mengaplikasikan teknologi aspal modifikasi dengan crumb rubber ini sejak tahun 1970 hingga 2011, dan hasilnya bahwa selama 4 dekade aspal crumb rubber dapat tahan lama dan memperpanjang umur layan jika direncanakan, diproduksi dan dilaksanakan dengan baik (Zhou et al., 2014). Sampel dengan kadar RejIRE 0,75\%, aspal Pen 60/70 dan aspal modifikasi SBS diuji sifat reologinya dan hasilnya ditampilkan pada Tabel 4.

Penambahan $15 \% \quad \mathrm{CR}$ dan variasi aditif meningkatkan titik lembek dan menurunkan penetrasi aspal. Tabel 3 menampilkan hasil pengujian dan membandingkannya dengan spesifikasi aspal modifikasi crumb rubber yang ada, yaitu spesifikasi khusus 3.6.3.2, ASTM 6D 6114, dan dari Caltrans. Dari ketiga spek dan standar tersebut disimpulkan bahwa parameter yang menjadi batasan adalah penetrasi, titik lembek, stabilitas penyimpanan dan elastic recovery, parameter yang lain tidak dipersyaratkan oleh semua.

Parameter penetrasi semua sampel memenuhi yaitu di atas $55 \mathrm{dmm}$. Parameter titik lembek hanya sampel dengan $0,75 \%$ RejIRE yang memenuhi. Sampel dengan kadar RejIRE 2\% melebihi batas maksimal nilai stabilitas penyimpanan, sedangkan empat sampel lainnya memenuhi. Nilai elastic recovery sampel dengan kadar RejIRE $0,75 \%$ dan $0,9 \%$ melebihi batas minimum yaitu $50 \%$, sehingga sampel dengan kadar aditif $0,75 \%$ yang memenuhi persyaratan. Sedangkan parameter daktilitas pada $25^{\circ} \mathrm{C}$, titik lembek setelah TFOT, daktilitas setelah TFOT tidak disyaratkan. Sehingga nilainya tidak mempengaruhi karakteristik aspal CR yang dihasilkan. Parameter viskositas pada $175^{\circ} \mathrm{C}$, ketiga spesifikasi mempersyaratkan. Namun sampel dengan kadar RejIRE $0,75 \%$ dan $0,9 \%$ yang belum didapatkan hasil pengujiannya (karena adanya perombakan birokrasi mengakibatkan perubahan fungsi instansi penguji. Maka untuk kegiatan pengujian ini tidak dapat diteruskan), selanjutnya akan digunakan sampel $0,75 \%$, dengan menganggap viskositasnya memenuhi syarat yaitu $\leq 3000$ Cst. Tabel 4 menunjukkan hasil pengujian DSR, dari tabel tersebut didapatkan bahwa aspal Pen 60/70 masuk ke dalam kelas PG 64-XX, sedangkan crumb rubber dengan kadar RejIRE0,75\% dan aspal yang dimodifikasi SBS masuk ke dalam kelas PG 70$\mathrm{XX}$. Untuk mengetahui tingkat penuaan aspal,

Tabel 3. Hasil pengujian aspal CR dengan variasi persentasi aditif

\begin{tabular}{|c|c|c|c|c|c|c|c|c|}
\hline \multirow{3}{*}{ Jenis pengujian } & \multicolumn{5}{|c|}{ Hasil pengujian } & \multicolumn{3}{|c|}{ Ketentuan } \\
\hline & \multicolumn{5}{|c|}{$\%$ aditif } & \multirow{2}{*}{$\begin{array}{c}\text { Bina } \\
\text { Marga } \\
(2015)\end{array}$} & \multirow{2}{*}{ ASTM } & \multirow{2}{*}{ Caltrans } \\
\hline & $\mathbf{0 , 7 5}$ & 0,9 & 1 & 2 & 3 & & & \\
\hline $\begin{array}{l}\text { Penetrasi pada } 25^{\circ} \mathrm{C}, 100 \mathrm{~g} \text {, } \\
5 \text { detik, dmm }\end{array}$ & 50 & 63 & 67 & 75 & 91 & $\geq 40$ & $\geq 25$ & $-* *$ \\
\hline Titik lembek, ${ }^{\circ} \mathrm{C}$ & 55,0 & 52,2 & 51,2 & 49,5 & 48,2 & $\geq 55$ & $\geq 57$ & $52-74$ \\
\hline $\begin{array}{l}\text { Daktilitas pada } 25^{\circ} \mathrm{C}, \\
5 \mathrm{~cm} / \text { menit, } \mathrm{cm}\end{array}$ & 19 & 21 & 22,5 & 32,5 & 35,5 & $-* *$ & $-* *$ & $-* *$ \\
\hline Berat jenis & 1,0552 & 1,0521 & 1,0497 & 1,0503 & 1,0463 & $\geq 1$ & $-* *$ & $-* *$ \\
\hline Titik nyala ( COC ) ${ }^{\circ} \mathrm{C}$ & 310 & 300 & 320 & 330 & 320 & $\geq 225$ & $\geq 232$ & $-* *$ \\
\hline Kehilangan berat (TFOT) \% & 0,0918 & 0,0865 & 0,0932 & 0,0893 & 0,0740 & $\leq 1$ & $-* *$ & $-* *$ \\
\hline Penetrasi setelah TFOT, $\%$ asli & 96 & 84 & 97 & 96 & 94 & $\geq 75 \%$ & $-* *$ & $-* *$ \\
\hline Titik lembek setelah TFOT, ${ }^{\circ} \mathrm{C}$ & 56,2 & 53,6 & 52,4 & 51,4 & 50,05 & $-* *$ & $-* *$ & $-* *$ \\
\hline Daktilitas setelah TFOT, cm & 17 & 18 & 18 & 28 & 30 & $-* *$ & $-* *$ & $-* *$ \\
\hline $\begin{array}{l}\text { Stabilitas penyimpanan : } \\
\text { perbedaan titik lembek }\left({ }^{\circ} \mathrm{C}\right)\end{array}$ & 1,15 & 1,85 & 1,8 & 2,3 & 0,9 & $\leq 2$ & $-* *$ & $-* *$ \\
\hline ER setelah TFOT, $\%$ & 55 & 51,25 & 45 & 35 & 25 & $\geq 50$ & $-* *$ & $-* *$ \\
\hline Viscositas Pada $175^{\circ} \mathrm{C}$ & - & - & 339Cst & $286 \mathrm{Cst}$ & 263 Cst & $\leq 3000 \mathrm{Cst}$ & $\leq 1,5 \mathrm{~Pa} . \mathrm{s}$ & 1,5-4 Pa.s \\
\hline
\end{tabular}


maka dapat dilihat dari aging factor yaitu rasio antara parameter $\mathrm{G}^{*} / \sin \delta$ setelah proses RTFOT dan $\mathrm{G}^{*} / \sin \delta$ original (You et al., 2011). Hal ini untuk mengetahui ketahanan deformasi pada umur awal perkerasan. Dari Tabel 4 didapatkan nilai aging factor aspal Pen 60/70, aspal modifikasi crumb rubber dan aspal modifikasi SBS berturutturut adalah 2,04, 2,01 dan 1,79. Maka aging factor aspal SBS lebih kecil dibandingkan dengan aspal Pen 60/70 dan aspal crumb rubber. Aging factor yang lebih rendah menandakan umur perkerasan yang lebih baik karena penuaan aspal atau perkerasan berjalan lebih lambat selama umur pelayanan jalan (Nissa et al., 2017).

\section{Sifat bahan agregat}

Agregat yang digunakan berasal dari Kabupaten Subang yang mana hasil pengujian sifat fisiknya disajikan pada Tabel 5 dan Gambar 1. Karakteristik bahan agregat yang digunakan memenuhi persyaratan. Gradasi yang digunakan adalah gradasi gabungan agregat campuran untuk AC wearing (spek umum Bina Marga, 2010).
Tabel 5, agregat dikelompokkan menjadi tiga ukuran $(\mathrm{mm})$, dimaksudkan agar pelaksanaan di laboratorium bisa lebih mudah dan detil dalam mendapatkan fraksi gabungan (Gambar 1). Bila dibagi menjadi dua, misalkan ukuran (8-20) $\mathrm{mm}$ dan ukuran (0-8) mm maka rentangnya relatif jauh dibanding bila dibagi menjadi tiga kelompok, hal ini meningkatkan resiko segregasi.

\section{Perancangan campuran beraspal panas}

Pada sub-bahasan reologi aspal telah disampaikan bahwa batasan viskositas aspal untuk penentuan temperatur pemadatan, tidak dapat diterapkan untuk campuran beraspal dengan bahan tambah, maka melalui percobaan Marshall (Kusnianti \& Affandi, 2013), langkah-langkahnya adalah sebagai berikut: (1) menyiapkan alat dan bahan, (2) membuat sampel Marshall dengan variasi temperatur pencampuran $\left(190^{\circ} \mathrm{C}, 180^{\circ} \mathrm{C}, 170{ }^{\circ} \mathrm{C}\right.$, dan $160{ }^{\circ} \mathrm{C}$ ) dan temperatur pemadatan (dan , $180^{\circ} \mathrm{C}, 170{ }^{\circ} \mathrm{C}, 160^{\circ} \mathrm{C}$, dan $150^{\circ} \mathrm{C}$ ), (3) masingmasing sampel diuji kepadatan dan VIMnya, (4) gambarkan pada grafik.

Tabel 4. Hasil pengujian dynamic shear rheologi

\begin{tabular}{|c|c|c|c|c|}
\hline Kondisi & Temperatur & $\begin{array}{c}\text { Aspal Pen } \\
60 / 70\end{array}$ & $\begin{array}{c}\text { Aspal CR } \\
\text { (RejIRE 0,75\%) }\end{array}$ & $\begin{array}{c}\text { Aspal } \\
\text { modifikasi SBS }\end{array}$ \\
\hline \multirow{3}{*}{$\begin{array}{l}\text { Original binder } \mathrm{G}^{*} / \sin \delta \text {, } \\
(1.000 \mathrm{~Pa})\end{array}$} & 64 & $1.221,0$ & 5.120 & 5.676 \\
\hline & 70 & 583,9 & 2.591 & 2.739 \\
\hline & 76 & 298,9 & 1.402 & 1.427 \\
\hline \multirow{3}{*}{ RTFO G*/sin $\delta,(2200 \mathrm{~Pa})$} & 64 & $2.490,0$ & 5.151 & 5.244 \\
\hline & 70 & $1.155,0$ & 2.815 & 2.561 \\
\hline & 76 & 567,8 & 1.612 & 1.350 \\
\hline \multirow{4}{*}{$\begin{array}{l}\text { PAV G* } \sin \delta \\
(5.500 .000 \mathrm{~Pa})\end{array}$} & 25 & $3.583 .000,0$ & 1.449 .000 & 5.218 .000 \\
\hline & 22 & $5.737 .000,0$ & 2.109 .000 & 8.712 .000 \\
\hline & 19 & & 3.264 .000 & \\
\hline & 16 & & 4.914 .000 & \\
\hline
\end{tabular}

Sumber: hasil uji DSR aspal Pen 60/70 dan aspal modifikasi SBS (Nissa et al., 2017)

Tabel 5. Sifat fisik dan gradasi agregat

\begin{tabular}{|c|c|c|c|c|c|}
\hline \multirow[b]{2}{*}{ No } & \multirow[b]{2}{*}{ Jenis pengujian } & \multirow[b]{2}{*}{ Metoda pengujian } & \multicolumn{3}{|c|}{ Hasil pengujian } \\
\hline & & & $\begin{array}{c}\text { Agregat } \\
(10-20) \mathrm{mm}\end{array}$ & $\begin{array}{l}\text { Agregat } \\
(5-10) \mathrm{mm}\end{array}$ & $\begin{array}{l}\text { Agregat } \\
(0-5) \mathrm{mm}\end{array}$ \\
\hline 1. & Abrasi, $(\%)$ & SNI 03-2417-2008 & 20,00 & - & - \\
\hline 2. & Setara pasir, $(\%)$ & SNI 03-4428-1997 & - & - & 57,00 \\
\hline \multirow[t]{4}{*}{3.} & Berat jenis & & & & \\
\hline & Bulk & SNI 03-1969-2008 & 2,63 & 2,66 & 2,63 \\
\hline & $S S D$ & SNI 03-1970-2008 & 2,66 & 2,68 & 2,68 \\
\hline & Apparent & & 2,76 & 2,77 & 2,77 \\
\hline 4. & Penyerapan, $(\%)$ & SNI $031969-2008$ & 1,70 & 1,50 & 1,90 \\
\hline 5. & Angularitas agregat halus, $(\%)$ & SNI 03-6877-2002 & - & - & 46,00 \\
\hline 6. & Angularitas agregat kasar, $(\%)$ & ASTM D 58212001 & $99,3 / 99,2$ & - & - \\
\hline 7. & Kelekatan terhadap aspal,(\%) & SNI 03-2439-2011 & - & $95+$ & - \\
\hline 8. & Partikel pipih dan lonjong, (\%) & ASTM D 47912005 & 2,40 & - & - \\
\hline 9. & Pelapukan, $(\%)$ & SNI 03-3407-1994 & 1,50 & 2,10 & 2,80 \\
\hline
\end{tabular}




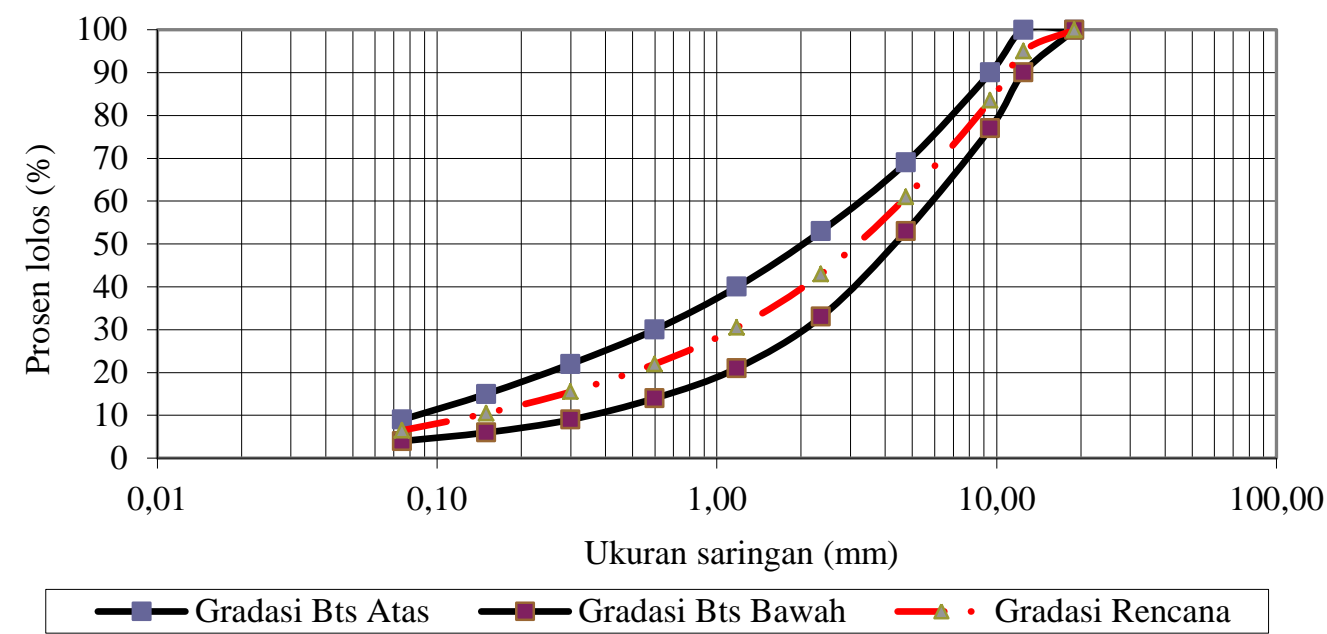

Gambar 1. Grafik gradasi gabungan agregat campuran AC wearing yang akan digunakan

Dari langkah-langkah tersebut didapatkan temperatur pencampuran dan pemadatan didasarkan pada hubungan antara temperatur pencampuran dan pemadatan dengan kepadatan, juga VIM yang diinginkan sesuai persyaratan spesifikasi.

Selanjutnya untuk mengetahui kinerja campuran beraspal dengan menggunakan aspal crumb rubber yang telah dimodifikasi adalah dengan melakukan pengujian karakteristik campuran beraspal dengan menggunakan alat Marshall, pengujian kekakuan campuran beraspal (modulus resilien), pengujian ketahanan campuran terhadap deformasi, pengujian ketahanan kelelahan campuran beraspal terhadap beban berulang (fatigue). Dengan dilakukan perencanaan campuran beraspal panas menggunakan gradasi laston $\mathrm{AC}$ wearing sesuai dengan spesifikasi umum Bina Marga TA 2010 revisi-3 dan membandingkannya dengan campuran beraspal panas dengan aspal Pen 60/70 dan campuran beraspal panas dengan menggunakan aspal modifikasi SBS. Perancangan campuran beraspal dari hubungan temperatur pencampuran dan pemadatan dengan kepadatan dan VIM didapatkan temperatur pencampuran pada $180^{\circ} \mathrm{C}$ dan pemadatan $170^{\circ} \mathrm{C}$. Karakteristik campuran beraspal panas pada Tabel 6 menunjukkan bahwa kepadatan, rongga di antara agregat, rongga dalam campuran, dan rongga terisi aspal ketiga jenis campuran beraspal panas memenuhi persyaratan. Stabilitas campuran beraspal panas dengan aspal modifikasi crumb rubber lebih besar dari pada yang menggunakan aspal Pen 60/70 namun lebih kecil dibanding yang menggunakan aspal modifikasi SBS.

Pengujian ketahanan campuran beraspal panas terhadap deformasi dibandingkan dengan campuran beraspal panas menggunakan aspal Pen 60/70 dan aspal Modifikasi SBS. Tabel 7 menunjukkan campuran beraspal panas menggunakan aspal modifikasi crumb rubber memiliki nilai stabilitas dinamis paling besar dibanding dua campuran lainnya. Hal ini dihasilkan dari nilai viskositas aspal crumb rubber yang tinggi mengakibatkan daya lekat campuran meningkat, sehingga menghasilkan campuran yang lebih tahan terhadap deformasi permanen. Namun demikian laju deformasi campuran beraspal panas dengan aspal crumb rubber hampir sama dengan yang menggunakan modifikasi SBS.

Tabel 6. Hasil pengujian karakteristik campuran beraspal panas

\begin{tabular}{lccc}
\hline \multicolumn{1}{c}{ Karakteristik campuran } & \multicolumn{3}{c}{ Tipe campuran } \\
\cline { 2 - 4 } & ACWCP 60 & ACWC CR & ACWCModifikasi SBS \\
\hline Kadar aspal optimum, (\%) & 6,03 & 6,000 & 6,00 \\
Kepadatan, (ton/m ${ }^{3}$ ) & 2,35 & 2,331 & 2,36 \\
Rongga diantara agregat, (\%) & 18,04 & 16,600 & 17,50 \\
Rongga dalam campuran (marshall), (\%) & 4,80 & 3,840 & 4,36 \\
Rongga terhadap campuran (PRD), (\%) & 2,20 & 3,380 & 2,48 \\
Rongga terisi aspal, (\%) & 76,30 & 76,920 & 75,08 \\
Stabilitas, (kg) & 986,00 & $1.032,000$ & 1305,00 \\
Kelelehan, (mm) & 3,80 & 3,600 & 3,84 \\
\hline
\end{tabular}


Tabel 7. Hasil pengujian ketahanan campuran terhadap deformasi

\begin{tabular}{|c|c|c|c|c|c|}
\hline \multirow{2}{*}{ Waktu } & \multirow{2}{*}{ Jumlah passing } & \multicolumn{3}{|c|}{ Tipe campuran } & \multirow{2}{*}{ Satuan } \\
\hline & & ACWC60 & ACWCCR & ACWCModifikasi SBS & \\
\hline 0 & 0 & 0,00 & 0,00 & 0,00 & $\mathrm{~mm}$ \\
\hline 1 & 21 & 1,26 & 1,20 & 0,83 & $\mathrm{~mm}$ \\
\hline 5 & 105 & 2,30 & 1,70 & 1,39 & $\mathrm{~mm}$ \\
\hline 10 & 210 & 3,04 & 1,95 & 1,76 & $\mathrm{~mm}$ \\
\hline 15 & 315 & 3,62 & 2,10 & 1,95 & $\mathrm{~mm}$ \\
\hline 30 & 630 & 5,12 & 2,39 & 2,30 & $\mathrm{~mm}$ \\
\hline 45 & 945 & 6,52 & 2,57 & 2,58 & $\mathrm{~mm}$ \\
\hline 60 & 1.260 & 7,81 & 2,72 & 2,78 & $\mathrm{~mm}$ \\
\hline \multicolumn{2}{|c|}{ Kecepatan deformasi } & 0,09 & 0,01 & 0,02 & $\mathrm{~mm} / \mathrm{menit}$ \\
\hline \multicolumn{2}{|c|}{ Stabilitas dinamis } & 492 & 4200 & 3088 & lintasan/mm \\
\hline
\end{tabular}

Sedangkan kecepatan deformasi campuran beraspal dengan aspal Pen 60/70 sangat cepat dibandingkan kedua campuran aspal lainnya. Hal ini berarti penambahan polimer pada aspal akan meningkatkan ketahanan campuran terhadap deformasi akibat beban berulang.Hasil pengujian modulus resilien dengan menggunakan alat Umatta disajikan pada Tabel 8. Hasil pengujian modulus resilien pada temperatur $45^{\circ} \mathrm{C}$ lebih kecil nilainya dibandingkan dengan pengujian pada temperatur $25^{\circ} \mathrm{C}$ dan $35{ }^{\circ} \mathrm{C}$. Hasil pengujian kelelahan campuran (fatigue) disajikan pada Gambar 2.

Tabel 8. Hasil pengujian modulus resilien

\begin{tabular}{|c|c|c|c|}
\hline \multirow[b]{2}{*}{$\begin{array}{c}\text { Temperatur } \\
\text { pengujian } \\
\left({ }^{\circ} \mathrm{C}\right)\end{array}$} & \multicolumn{3}{|c|}{ Modulus resilien (Mpa) } \\
\hline & $\begin{array}{c}\mathrm{ACWCP} \\
60\end{array}$ & ACWCCR & $\begin{array}{c}\text { ACWC } \\
\text { Modifikasi } \\
\text { SBS }\end{array}$ \\
\hline 25 & 3.492 & 1.562 & 2.645 \\
\hline 35 & 921 & 463 & 814 \\
\hline 45 & 221 & 247 & 343 \\
\hline
\end{tabular}

Pada Tabel 8 diperlihatkan bahwa temperatur mempengaruhi nilai modulus resilien. Nilai modulus resilien pada temperatur $25^{\circ} \mathrm{C}$ dan $35^{\circ} \mathrm{C}$ campuran beraspal dengan aspal Pen 60/70 paling tinggi dibanding dua campuran lainnya. Tetapi pada temperatur tinggi yaitu $45^{\circ} \mathrm{C}$ campuran beraspal menggunakan aspal modifikasi SBS dan crumb rubber berturut-turut nilai modulus resilien lebih tinggi dari pada campuran beraspal dengan menggunakan aspal Pen 60/70. Hal ini diakibatkan oleh penambahan polimer pada campuran beraspal. Batasan regangan yang digunakan dalam pengujian fatique adalah 100 microstrain jika ingin perkerasan lentur diharapkan berumur panjang (perpetual pavement atau longlife pavement). Regangan di bawah lapisan perkerasan harus dijaga sebesar 100 microstrain, maka dijaga beban yang lewat di jalan tersebut agar tidak mengakibatkan regangan di atas batasan tersebut (Suaryana et al., 2014).Nah untuk melakukan uji kelelahan dengan 100 microstrain ini akan membutuhkan waktu yang sangat lama.

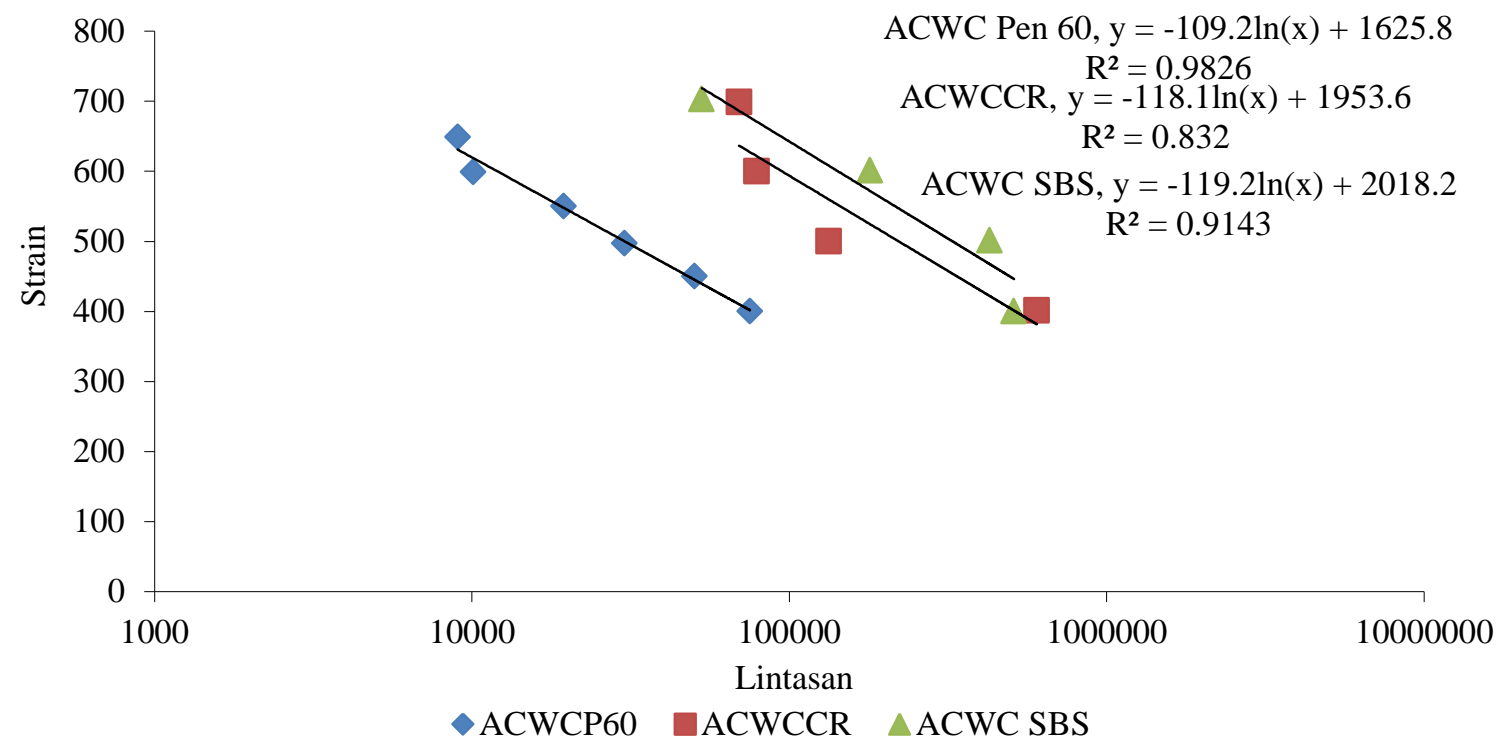

Gambar 2. Grafik kelelahan campuran beraspal panas 


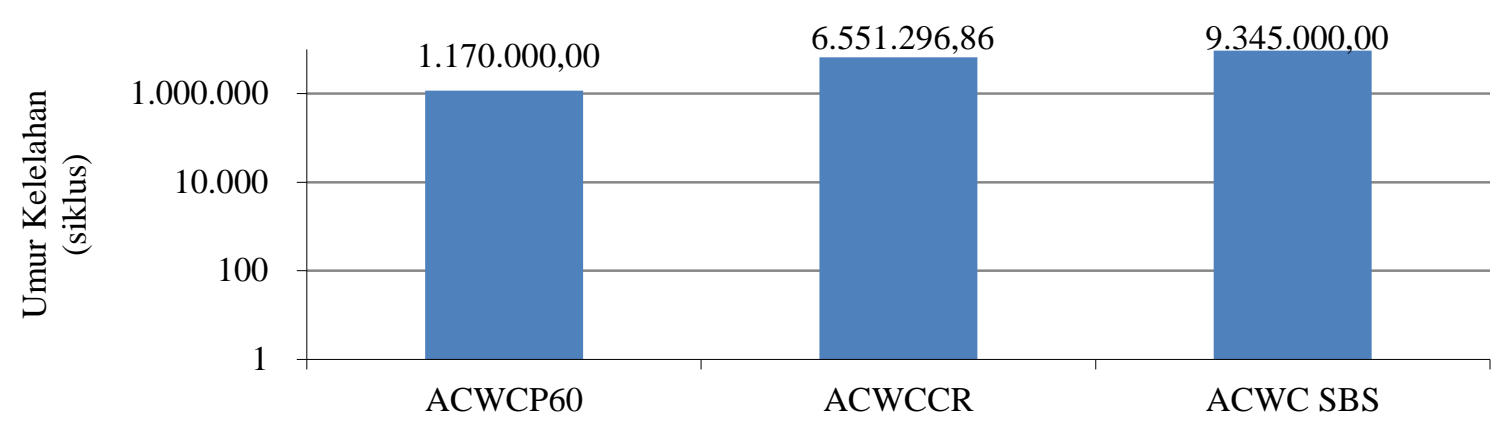

Gambar 3. Grafik kelelahan campuran beraspal panas pada 100 microstrain

Maka digunakanlah persamaan regresi yang menganggap hasilnya valid, dengan melihat nilai $\mathrm{R}$ square-nya. Ketahanan lelah masing-masing tipe campuran diperlihatkan pada Gambar 3. Dapat dilihat bahwa ketahanan terhadap lelah Campuran beraspal dengan tambahan polimer lebih tinggi dibandingkan campuran beraspal tanpa polimer.

\section{Kesimpulan}

Penambahan RejIRE dengan kadar $0,75 \%$ ke dalam aspal modifikasi crumb rubber dapat menurunkan viskositas aspal modifikasi crumb rubber serta memenuhi persyaratan yang diminta Spesifikasi Khusus 3.6.3.2, ASTM 6D 6114, atau dari Caltrans. Penilaian kinerja campuran beraspal panas dengan menggunakan aspal modifikasi SBS secara keseluruhan lebih baik dibanding dengan campuran beraspal panas dengan aspal crumb rubber dan campuran beraspal panas dengan aspal Pen 60/70. Kinerja campuran beraspal panas dengan aspal crumb rubber lebih baik daripada campuran beraspal panas dengan aspal Pen 60/70.

Metode untuk mendapatkan aspal dan $15 \%$ crumb rubber adalah dengan memanaskan aspal Pen60/70 pada temperatur $140^{\circ} \mathrm{C}$ lalu tambahkan crumb rubber sambil diaduk dengan kecepatan $6.000 \mathrm{rpm}$ selama 60 menit pertahankan temperature pemanasannya (Mulyani \& Hamdani, 2017). Percobaan di laboratorium belum tentu mewakili skala lapangan, untuk itu perlu dibuat penyesuaian bila akan dilaksanakan dalam skala lapangan.

\section{Ucapan Terima Kasih}

Penulis mengucapkan banyak terima kasih kepada Kepala Pusjatan, Kementerian PUPR, dan Kepala Balai Litbang Perkerasan Jalan dan berbagai pihak yang telah membimbing dalam penyusunan makalah ini hingga diterbitkan.

\section{Daftar Pustaka}

Affandi, F. (2009). Sifat Campuran Beraspal Panas dengan Asbuton Butir. Jurnal Jalan-Jembatan, 26(2), 93-106.
Ambaiowei, D. C., \& Tighe, S. L. (2013). Optimizing Crumb rubber Modifiers (CRM) and Reclaimed Asphalt Pavements (RAP) in Typical Ontario Hot Mix Asphalt. Retrieved April 19, 2018, from https://www.researchgate.net/profile/ Doubra_Ambaiowei/publication/258698743_Opti mizing_Crumb_Rubber_Modifiers_CRM_and_Re claimed_Asphalt_Pavements_RAP_in_Typical_O ntario_Hot_Mix_Asphalt/links/02e7e528d4f9e676 cf000000.pdf

American Standard Testing Material. (2009). Standard Terminology Relating to Materials for Roads and Pavements, American Society for Testing and Materials. ASTM International Standards, Volume 04.03, Road and Paving Materials, Vehicle-Pavement Systems. Conshocken, ASTM.

Bahia, H., Golalipur, A., \& Coenen, A. R. (2012). Comparing Effects Of Crumb rubber and Synthetic Polymers On Hot Mix Asphalt Performance. Retrieved April 23, 2018, from http://www. consulpav.com/shop/?product=comparing-effectsof-crumb-rubber-and-synthetic-polymers-on-hotmix-asphalt-performance

Caltrans. (2015). Asphalt rubber usage guide, Sacramento: State of California Departement of Transportation.

Fauziah, M. \& Handaka, A. (2017). Pemanfaatan Aspal Modifikasi SBS E-55 untuk Menahan Penurunan Kinerja Akibat Rendaman Air Hujan pada Campuran Split Mastic Asphalt. Jurnal Transportasi, 17(I), 11-20.

Hermadi, M., \& Ronny, Y. (2015). Pengaruh Penambahan Lateks Alam terhadap Sifat Reologi Aspal. Jurnal HPJI, 1(2), 105-114.

Huang, Y. H. (2004). Pavement analysis and design ( $2^{\text {nd }}$ ed.). Kentucky: Pearson Education Inc.

Indonesia, Kementerian Pekerjaan Umum. Direktorat Jenderal Bina Marga. (2010). 
Spesifikasi umum (revisi 3). Jakarta: Kementerian Pekerjaan Umum.

Indonesia, Kementerian Pekerjaan Umum. Direktorat Jenderal Bina Marga. (2015). Spesifikasi khusus interim seksi 6.3 campuran beraspal panas dengan aspal yang dimodifikasi crumb rubber atau asbuton (Skh-3.6.3.2), Jakarta: Kementerian Pekerjaan Umum.

Kusnianti, N., \& affandi, F. (2013). Pengaruh Jenis Aspal pada Temperatur Pemadatan Berkaitan dengan Workability dari Campuran Beraspal Panas. Jurnal Jalan dan Jembatan, 30(2), 97-111.

Mulyani, S., \& Hamdani, D. (2017). Teknik Pencampuran yang Optimal antara Crumb Rubber dan Aspal Pen 60/70, Jurnal Jalan dan Jembatan, 34(1), 9-20.

Nissa, Anita J., Rahman, H., Subagio, B. S., \& Wibowo, S. S. (2017). Kinerja Campuran Beraspal Hangat Laston Lapis Antara (AC-BC) dengan Aspal Modifikasi Econuska, Tesis Program Magister Sistem Teknik dan Jalan Raya, Bandung: Institut Teknologi.

Nono. (2016). Pengembangan teknologi aditif untuk campuran beraspal yang menggunakan RAP dan asbuton. Naskah Ilmiah, Bandung: Pusat Litbang Jalan dan Jembatan.

Nono. (2017). Campuran beraspal hemat agregat dan aspal, Jakarta: Lipi Press.

Nono \& Mahmud, S. (2016). Teknologi campuran beraspal panas bergradasi menerus, Bandung: Pusat Penelitian dan Jalan dan Jembatan.

Pangaraya, D. K. (2015). Laboratorium Study of Asphalt Modifikasi SBS E-55 Polymer Modified Application on Asphalt Concrete Wearing Course
(AC-WC). Journal of The Civil Engineering Forum, 1(3).

Pavement Interactive. (2016). Dynamic Shear Rheometer, Retrieved May 17, 2018, from http://www.pavementinteractive.org/dynamicshear-rheometer/

Shatnawi, S. (2011). Comparisons of Rubberized Asphalt Binders: Asphalt Rubber and Terminal Blend Second Update, Retrieved September 15, 2017, from http://www.rubberpavements.org/ Library_Information/White_Paper_Comparisons_o f_AR_TB_Update_FINAL_20111123.pdf

Suaryana, N. (2015). Evaluasi Stabilitas Dinamis dan Flow Number sebagai Parameter Ketahanan Campuran Beraspal terhadap Deformasi Permanen, Jurnal Jalan dan Jembatan, 32(3), 156-170.

Suaryana, N., Kosasih, D,. \& Ronny, Y. (2014). Perpetual pavement/long lasting asphalt pavement. Naskah Ilmiah, Bandung: Pusat Litbang Jalan dan Jembatan.

Suaryana, N., \& Kusnianti, N. (2016). Karakteristik Campuran Hangat Asbuton dengan Bahan Tambah Berbasis Parafin, Jurnal Jalan dan Jembatan, 33 (2), 80-91.

Suroso, T. W. (2008). Faktor-Faktor Penyebab Kerusakan Dini pada Perkerasan Jalan, Jurnal Jalan-Jembatan, 25(3), 272-290.

You, Z., et al. (2011). Laboratory evaluation of warm mix asphalt, Michigan, USA: Michigan Department of Transportation.

Zhou, H., Holikatti, S., \& Vacura, P. (2014). Caltrans use of Scrap Tires in Asphalt Rubber Products: a Comprehensive Review. Journal of traffic and Transportation Engineering (English Edition), 1(1), 39-48. 